- Supporting Information -

\title{
Dealing with Climate Parameters in the Fabrication of Perovskite Solar Cells under Ambient Conditions
}

Lidia Contreras-Bernal, ${ }^{+, *}$, Antonio Riquelme ${ }^{\dagger}$, Juan Jesús Gallardo, ${ }^{*}$ Javier Navas,,$*$

Jesús Idígoras ${ }^{\dagger}$, Juan A. Antat,*

†Área de Química Física, Universidad Pablo de Olavide, E-41013, Sevilla, Spain

†Departamento de Química Física, Facultad de Ciencias, Universidad de Cádiz, E11510 Puerto Real.

Corresponding authors

* 1conber@upo.es (Lidia Contreras-Bernal);

* anta@upo.es (Juan A. Anta)

Number of pages: S1-S8

Number of figures: S1-S11

Number of tables: S1-S2 
Table S1. Photovoltaic parameter statistics of $\mathrm{MAPbI}_{3}$ devices prepared under environmental conditions. Data were obtained in the reverse scan under AM1.5-1 sun illumination for perovskite films deposited from a solution precursor with a $\mathrm{DMSO}: \mathrm{Pb}^{2+}$ ratio of $0.75 ; 4$ devices of each configuration were measured.

\begin{tabular}{ccccccc}
$\mathbf{R H}[\%]$ & $\mathbf{T}[\mathbf{K}]$ & $\mathbf{W V P}[\mathrm{kPa}]$ & $\mathbf{J}_{\mathbf{s c}}\left[\mathbf{m A} \cdot \mathbf{c m}^{-2}\right]$ & $\mathbf{V}_{\mathbf{O C}}[\mathbf{V}]$ & $\mathbf{F F}[\%]$ & EFF [\%] \\
\hline 41 & 300 & 1.47 & $20.95 \pm 1.04$ & $1.04 \pm 0.02$ & $74.1 \pm 0.9$ & $16.2 \pm 1.2$ \\
39 & 301 & 1.46 & $22.88 \pm 0.57$ & $1.04 \pm 0.01$ & $67.7 \pm 2.1$ & $16.0 \pm 0.8$ \\
49 & 301 & 1.85 & $16.40 \pm 0.97$ & $0.97 \pm 0.02$ & $68.0 \pm 2.9$ & $10.8 \pm 1.1$
\end{tabular}

Table S2. Intensity ratio between the hexagonal $\mathrm{PbI}_{2}$ peak $\left(12.6^{\circ}\right)$ and tetragonal $\mathrm{MAPbI}_{3}\left(14.1^{\circ}\right)$ peak for films deposited at 1.01 and $1.82 \mathrm{kPa}(299$ and $301 \mathrm{~K} ; 30 \%$ and $48 \%$ relative humidity, respectively).

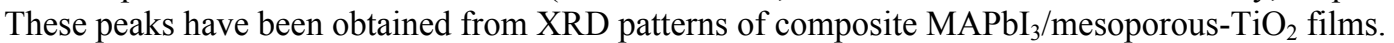

\begin{tabular}{|c|c|c|c|c|c|c|}
\hline \multirow{2}{*}{$\begin{array}{c}\text { Ratio } \\
\text { DMSO:Pb }\end{array}$} & \multirow{2}{*}{ WVP [kPa] } & \multicolumn{2}{|c|}{$\mathrm{Pbl}_{2}$} & \multicolumn{2}{|c|}{$\mathrm{MAPbl}_{3}$} & \multirow{2}{*}{$\mathbf{I}_{1} / \mathbf{I}_{2}$} \\
\hline & & $2 \theta$ & $I_{1}$ & $2 \theta$ & $\mathbf{I}_{2}$ & \\
\hline \multirow{2}{*}{0} & 1.01 & 12.65 & 740.9 & 14.08 & 4539.6 & 0.163 \\
\hline & 1.82 & 12.52 & 1194.4 & 14.02 & 756.0 & 1.58 \\
\hline \multirow{2}{*}{0.5} & 1.01 & 12.65 & 472.4 & 14.10 & 7424.5 & 0.064 \\
\hline & 1.82 & 12.58 & 1292.6 & 14.02 & 1504.1 & 0.859 \\
\hline \multirow{2}{*}{0.75} & 1.01 & 12.63 & 498.7 & 14.10 & 7881.7 & 0.064 \\
\hline & 1.82 & 12.58 & 453.5 & 14.00 & 2334.5 & 0.194 \\
\hline \multirow{2}{*}{1} & 1.01 & 12.61 & 1690.6 & 14.08 & 6343.2 & 0.266 \\
\hline & 1.82 & 12.52 & 675.51 & 14.00 & 1356.3 & 0.498 \\
\hline \multirow{2}{*}{1.25} & 1.01 & 12.61 & 1241.8 & 14.08 & 4829.2 & 0.257 \\
\hline & 1.82 & 12.54 & 675.51 & 14.00 & 1356.3 & 0.543 \\
\hline
\end{tabular}

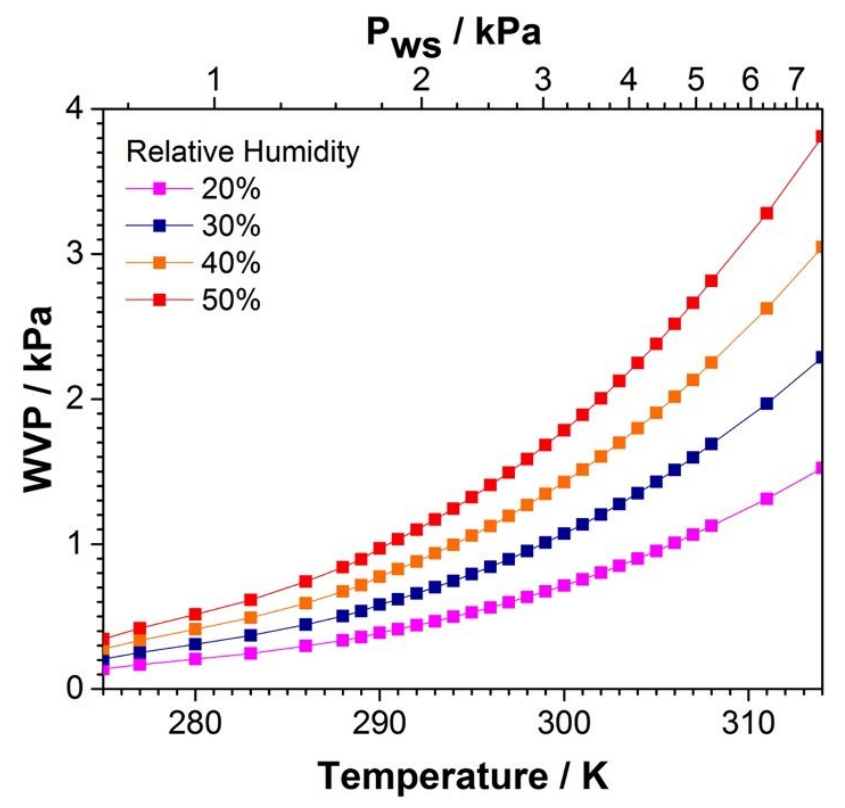

Figure S1. Water vapour pressure versus temperature for various values of the relative humidity. 

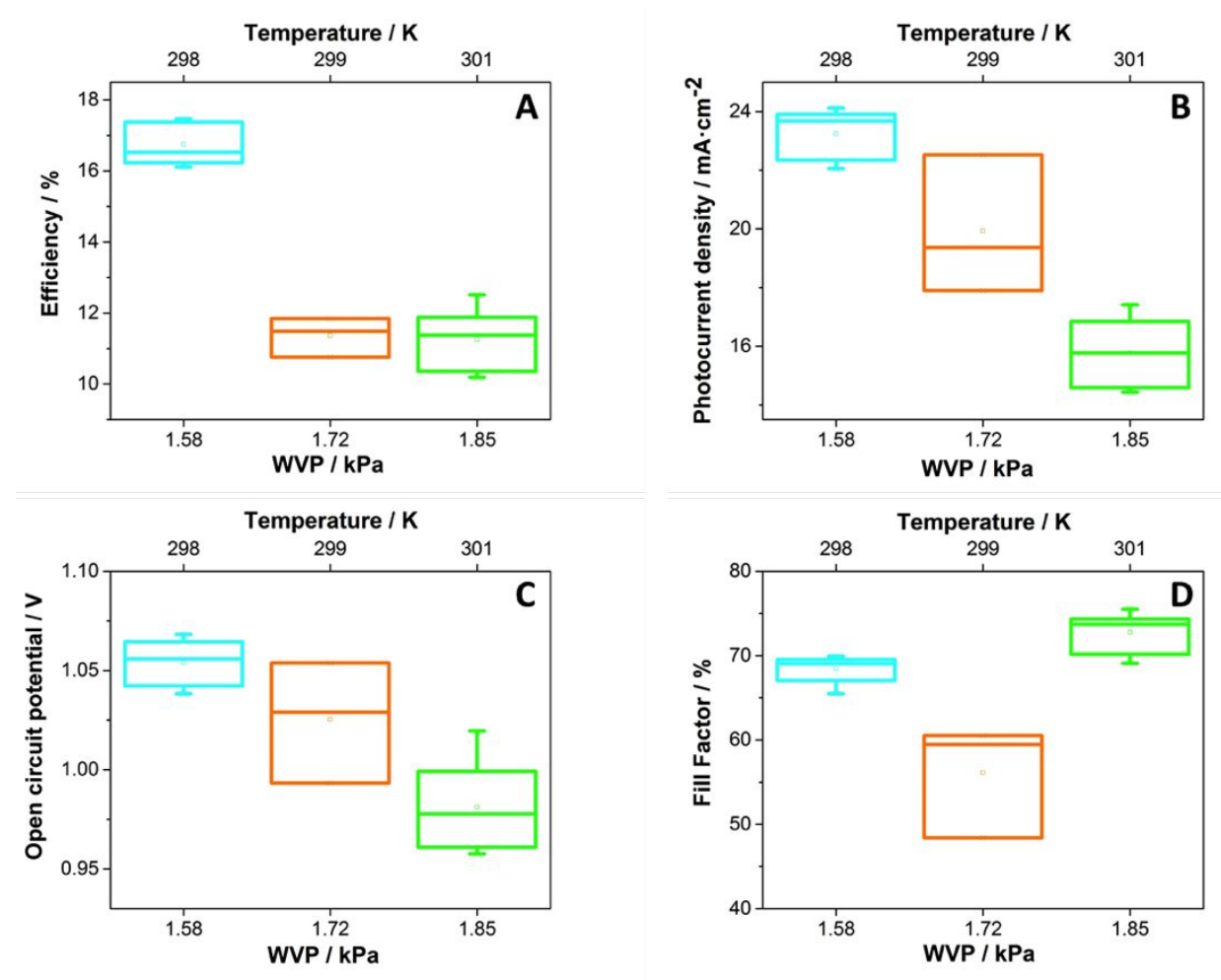

Figure S2. Photovoltaic parameter statistics (A: efficiency; B: Photocurrent density; C: Potential; D: Fill factor) using analysis of variance (ANOVA) of $\mathrm{MAPbI}_{3}$ devices prepared under different temperature conditions and at a relative humidity of 50\%. Data were obtained in the reverse scan under AM1.5 - 1 sun illumination for perovskite films deposited from a solution precursor with a DMSO: $\mathrm{Pb}^{2+}$ ratio of 0.75 . Note that at least 6 devices of each configuration were measured.

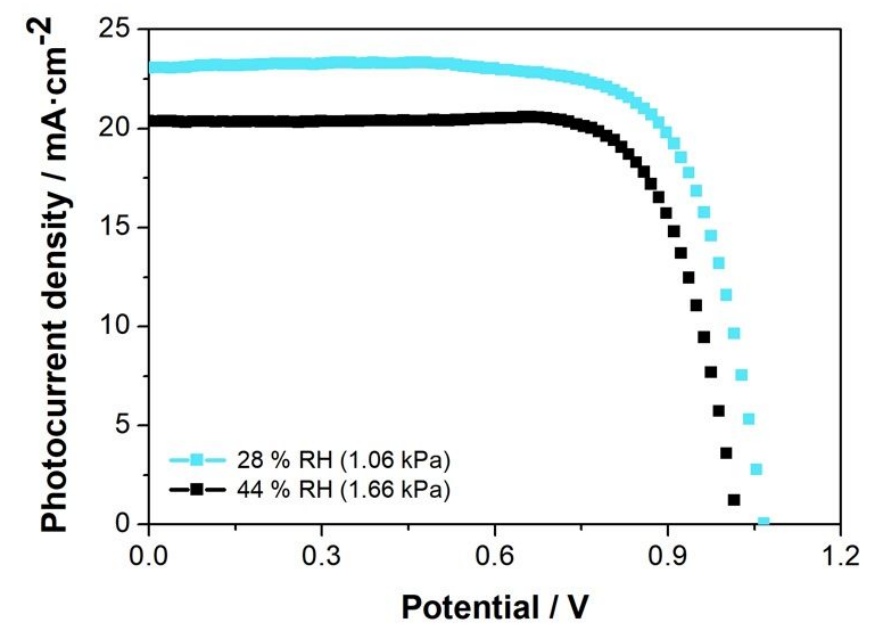

Figure S3. Current-voltage curves of $\mathrm{MAPbI}_{3}$ perovskite devices prepared at two different values of $\mathrm{RH}$ but at the same temperature of $301 \mathrm{~K}$ (resulting in different WVPs, as indicated). The curves have been measured in the reverse scan under 1 sun-AM 1.5 illumination and using a mask of $0.16 \mathrm{~cm}^{2}$. For all three cases, perovskite films were deposited from a solution precursor with a $1.0 \mathrm{DMSO}: \mathrm{Pb}^{2+}$ ratio . 

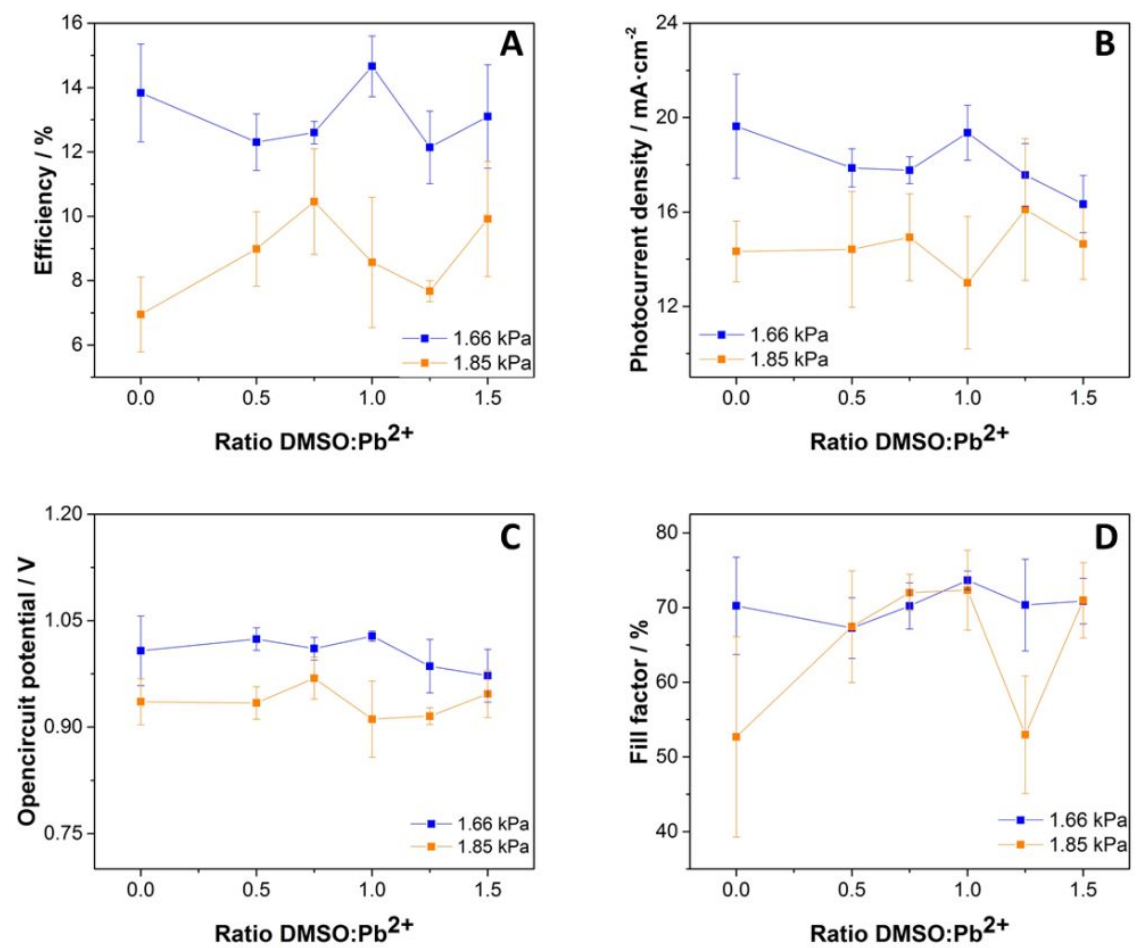

Figure S4. Photovoltaic parameters (A: efficiency; B: Photocurrent density; C: Potential; D: Fill factor) of $\mathrm{MAPbI}_{3}$ devices prepared from precursor solution with various $\mathrm{DMSO}: \mathrm{Pb}^{2+}$ ratios for two water vapour pressures (WVP). Data were obtained in the reverse scan under AM1.5 - 1 sun illumination for perovskite solar devices fabricated at $301 \mathrm{~K}$ and $44 \%$ and $49 \%$ R.H (1.66 $\mathrm{kPa}$ and $1.85 \mathrm{kPa}$, respectively).
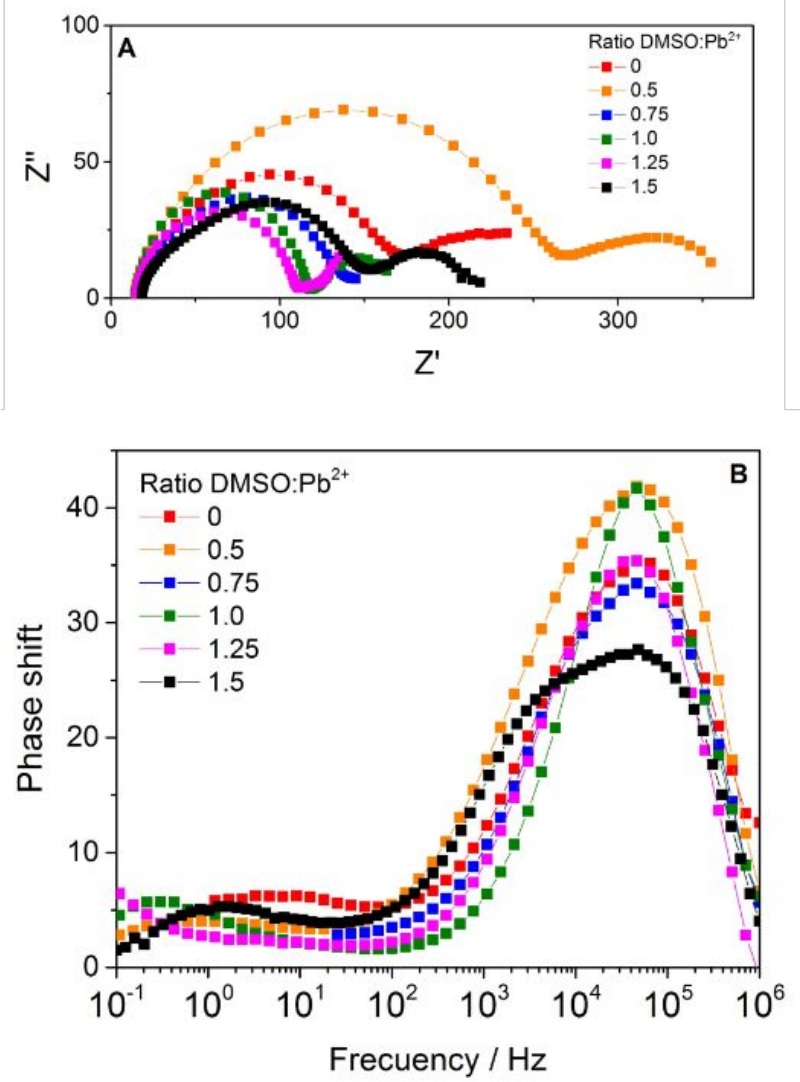

Figure S5. Impedance Nyquist (A) and Bode (B) plots for $\mathrm{MAPbI}_{3}$ devices prepared with several 
DMSO: $\mathrm{Pb}^{2+}$ ratios at $1.66 \mathrm{kPa}$. Data obtained under red illumination $(635 \mathrm{~nm})$ are shown. The opencircuit potential generated by the illumination is $0.911 \mathrm{~V}$.

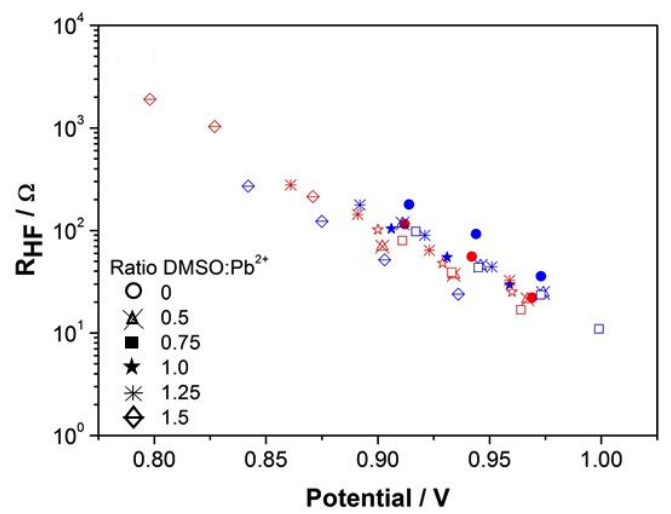

Figure S6. High-frequency resistance data as extracted from impedance spectroscopy measurements for $\mathrm{MAPbI}_{3}$ devices prepared from precursor solutions with various $\mathrm{DMSO}: \mathrm{Pb}^{2+}$ ratios and deposited at a WVP of $1.66 \mathrm{kPa}$. Experiments were run using an excitation wavelength of $635 \mathrm{~nm}$ (red symbols) and $465 \mathrm{~nm}$ (blue symbols).
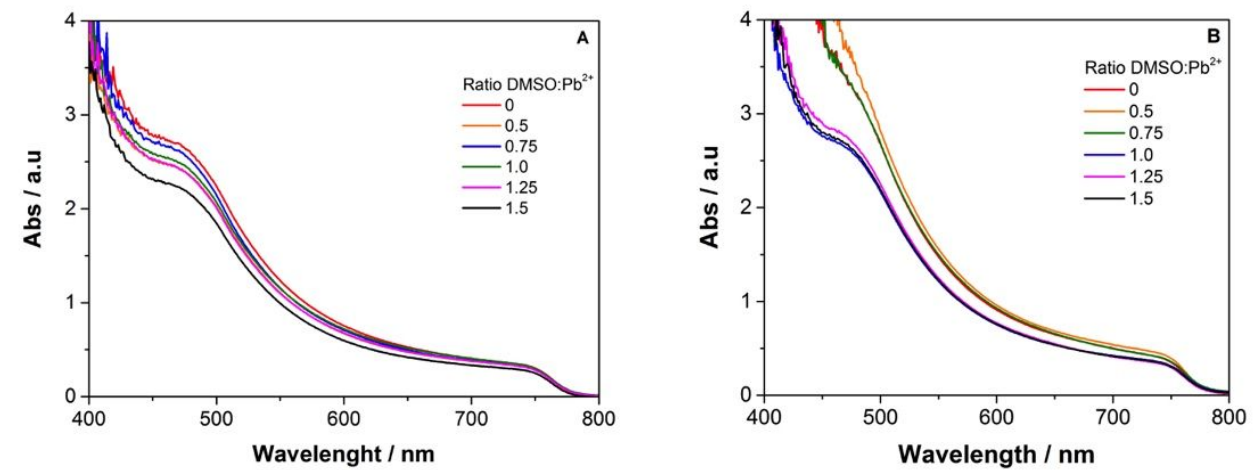

Figure S7. Optical absorption spectra of $\mathrm{MAPbI}_{3}$ films deposited on $\mathrm{TiO}_{2}$ substrates from precursor solutions with several DMSO: $\mathrm{Pb}^{2+}$ ratios. Data obtained for two WVP values: $1.85 \mathrm{kPa}(\mathbf{A})$ and $1.66 \mathrm{kPa}$ (B). 


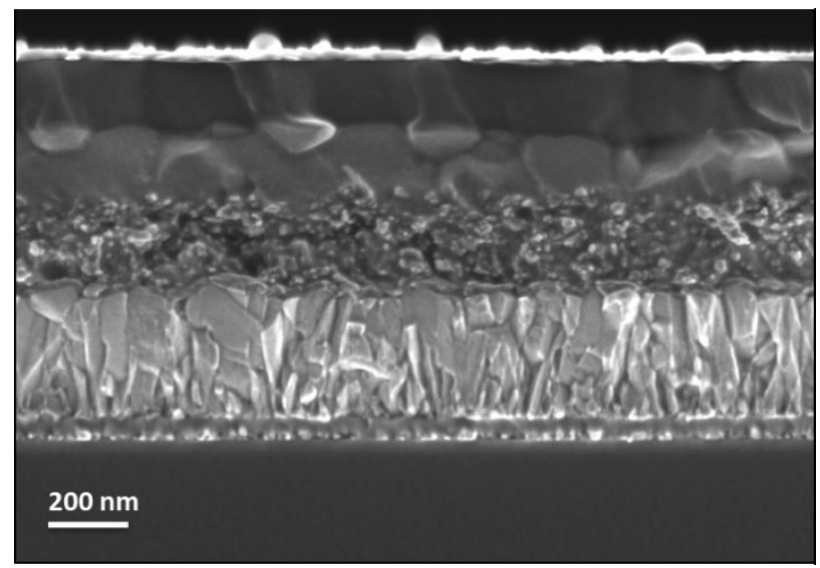

Figure S8. Cross-sectional image obtained by scanning electron microscopy (SEM) of a FTO/c- $\mathrm{TiO} 2 / \mathrm{m}^{-}$ $\mathrm{TiO}_{2} / \mathrm{MAPbI}_{3} / \mathrm{Spiro} / \mathrm{Au}$ stack. The perovskite film was deposited from a precursor solution with a ratio DMSO: $\mathrm{Pb}^{2+}$ equal to zero at a WVP of $1.65 \mathrm{kPa}$.
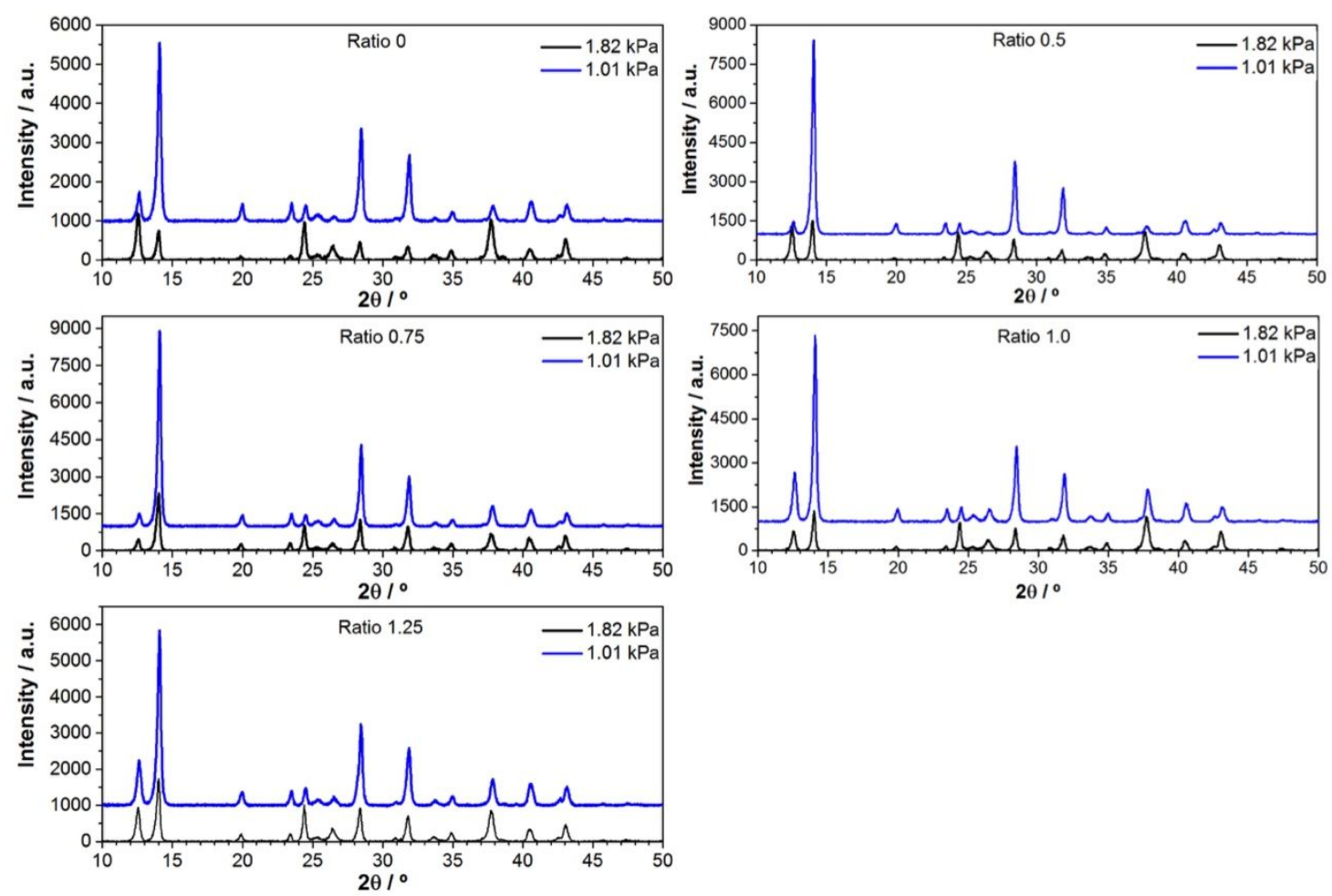

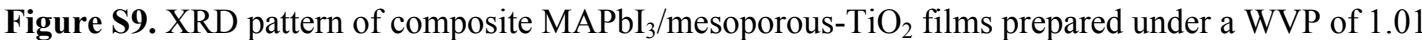
$\mathrm{kPa}$ (299 and $30 \%$ relative humidity) and $1.82 \mathrm{kPa}(301 \mathrm{~K}$ and $48 \%$ relative humidity). 


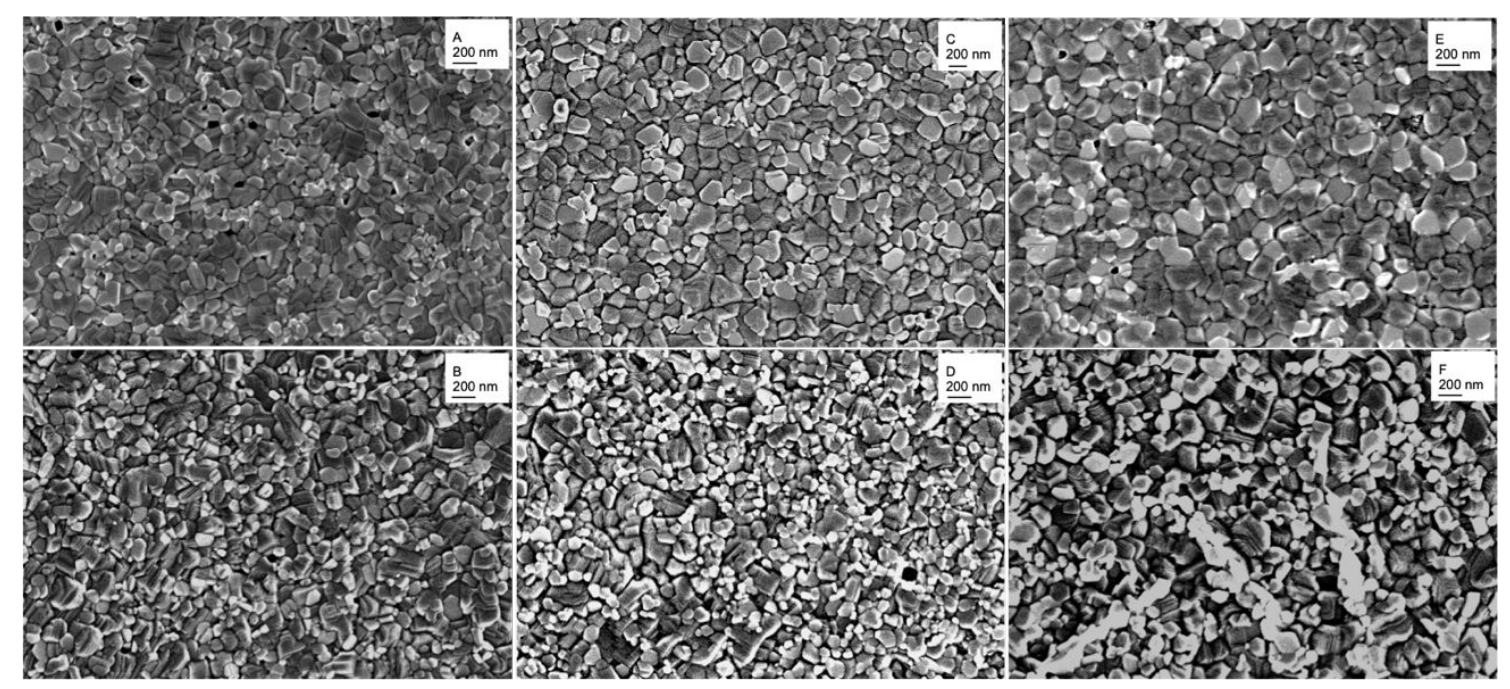

Figure S10. Top-view scanning electron microscopy (SEM) images for $\mathrm{MAPbI}_{3}$ films from precursor solution with DMSO: $\mathrm{Pb}^{2+}$ ratio of $1.5(\mathbf{A}$ and $\mathbf{B}), 1.0(\mathbf{C}$ and $\mathbf{D})$, and $0.5(\mathbf{E}$ and $\mathbf{F})$, and deposited at a WVP of $1.66 \mathrm{kPa}(\mathbf{A}, \mathbf{C}$ and $\mathbf{E})$ and $1.85 \mathrm{kPa}(\mathbf{B}, \mathbf{D}$ and $\mathbf{F})$.

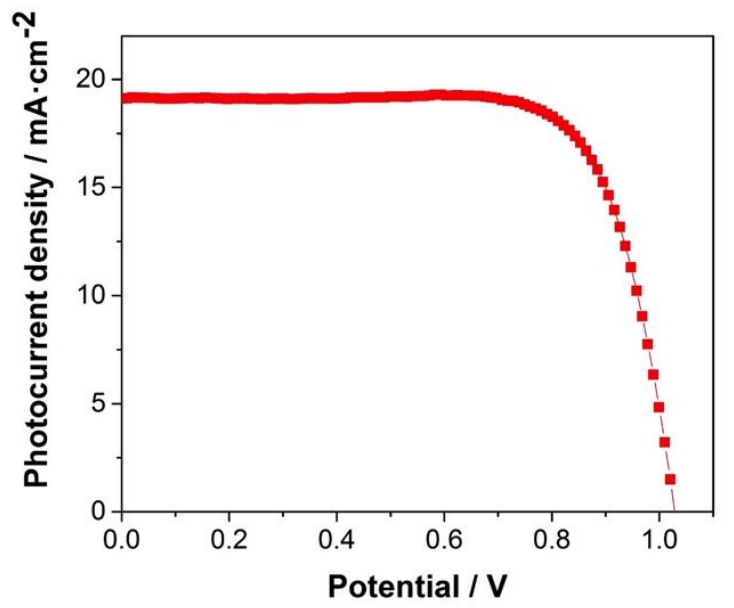

Figure S11. Current-voltage curve of the best $\mathrm{FA}_{0.83} \mathrm{MA}_{0.17} \mathrm{PbI}_{3}$ devices prepared at a WVP of $1.56 \mathrm{KPa}$ ( $302 \mathrm{~K}$ and $39 \%$ relative humidity) The curves have been measured in the reverse scan under 1 sun-AM 1.5 illumination and using a mask of $0.16 \mathrm{~cm}^{2}$. 